\title{
Bibliotecas escolares e Biblioteconomia escolar no Brasil ${ }^{1}$
}

\author{
School libraries and school librarianship in Brazil
}

\author{
Bernadete Santos Campello \\ Doutora em Ciência da Informação pela Universidade Federal de Minas Gerais - UFMG. \\ Professora titular da Escola de Ciência da Informação da Universidade Federal de Minas Gerais - UFMG. \\ E-mail: bscampello@gmail.com
}

\section{Resumo}

Este trabalho tem como objetivo traçar um panorama da situação das bibliotecas escolares no Brasil e de questões que afetam seu desenvolvimento, utilizando a metodologia de análise textual. Dois pontos emergiram da análise: 1) o surgimento de grupos de pesquisa acadêmica desde a década de 1990 e o consequente aumento dos estudos sobre biblioteca escolar indicam que a base teórica para a melhoria dessas instituições está sendo construída e 2) a promulgação, em 24 de maio de 2010 da Lei 12.244, que obriga que cada escola brasileira de educação básica tenha uma biblioteca representou uma grande conquista, mas sua eficácia ainda precisa ser comprovada.

Palavras-chave: biblioteca escolar, biblioteconomia escolar

\begin{abstract}
This paper aims to outline a summary of the situation of school libraries in Brazil and of issues that affect their development, using the methodology of textual analysis. Two points arise from the analysis: 1) the emergence of academic research groups since the 1990s and the consequent increase in school library studies indicate that the theoretical foundation for the improvement of these institutions is being built and 2) the enactment, on May 24, 2010 of Act 12244 which enforces that each Brazilian school of basic education has a library represented a great achievement but its effectiveness remains to be proven.
\end{abstract}

Keywords: School libraries, School Librarianship, Brazil

\footnotetext{
1 Trabalho publicado originalmente em inglês, nos anais da 43th IASL International Association on School Librarianship (IASL) Conference and 18th Forum on International Research in School Librarianship, que ocorreu em Moscou, Rússia, de 25 a 30 de agosto de 2014. A publicação desta versão em português foi devidamente autorizada pela IASL.
}

Bibl. Esc. em R., Ribeirão Preto, v. 4, n. 1, p. 1-25, 2015. 
Bibliotecas escolares e Biblioteconomia escolar no Brasil

\section{Introdução}

As primeiras bibliotecas escolares surgiram no Brasil no século XVI, nos conventos dos padres jesuítas que chegaram ao país com a pretensão de catequizar os índios e instruir os primeiros colonos portugueses. No século XVII, outras ordens religiosas se estabeleceram no país e suas instalações abrigavam bibliotecas que apoiavam o ensino dessas instituições (SILVA, 2011). Embora os conventos tenham sofrido um período de decadência no século XVIII, as ordens religiosas continuaram a manter colégios, que passaram a atender a elite da sociedade da época: filhos de empresários, intelectuais, funcionários do governo, o que ocorre até hoje. Atualmente, no âmbito do ensino privado, além das escolas religiosas, há uma gama de instituições escolares leigas, com diferentes orientações pedagógicas.

No âmbito das escolas públicas, as bibliotecas escolares surgiram por volta da década de 1930, quando a educação começou a sofrer influência de métodos de aprendizagem inovadores, estimulados pelo movimento da chamada Escola Nova (SILVA, 2011), coincidindo com a criação de cursos de biblioteconomia no país. Atualmente, embora as diretrizes curriculares para a educação básica (BRASIL, 1997) recomendem um ensino com base em teorias construtivistas e considerem a biblioteca escolar como recurso fundamental de aprendizagem, diversos estudos apontam para a precariedade da situação dessas instituições.

\section{Objetivo e metodologia}

Este trabalho tem como objetivo traçar uma síntese da situação das bibliotecas escolares no Brasil e das questões que afetam o seu desenvolvimento. A metodologia utilizada foi a análise textual, feita com base em documentos relevantes, selecionados entre aqueles que apresentam dados estatísticos, além de estudos críticos e avaliativos sobre o panorama das bibliotecas escolares brasileiras. 
Bernadete Santos Campello

\section{Bibliotecas escolares}

Os dados quantitativos mais recentes sobre a educação básica² no Brasil resultam do Censo Escolar de 2013, de responsabilidade do Ministério da Educação - MEC. O documento síntese do Censo revela que "nos 190.706 estabelecimentos de educação básica do País, estão matriculados 50.042.448 alunos, sendo 41.432 .416 (82,8\%) em escolas públicas e 8.610.032 $(17,2 \%)$ em escolas da rede privada. As redes municipais são responsáveis por quase metade das matrículas $(46,4 \%)$, o equivalente a 23.215 .052 alunos, seguida pela rede estadual, que atende a 35,8\% do total, 17.926.568 alunos. A rede federal, com 290.796 matrículas, participa com $0,6 \%$ do total" (BRASIL, 2014, p. 12).

O referido documento apresenta a porcentagem de bibliotecas/salas de leitura em relação ao número de escolas e ao de matrículas, dos níveis fundamental e médio de ensino e por vinculação da escola. A TAB. 1 apresenta essas porcentagens.

TABELA 1 - Alunos de escolas de ensino fundamental e médio com acesso à biblioteca/sala de leitura

\begin{tabular}{|l|l|l|l|l|l|}
\hline Nível de ensino & Vinculação & $\begin{array}{l}\mathrm{N}^{\mathbf{0}} \text { de } \\
\text { escolas }\end{array}$ & $\begin{array}{l}\% \text { de escolas } \\
\text { com de } \\
\text { biblioteca/sala } \\
\text { de leitura }\end{array}$ & $\begin{array}{l}\mathrm{N}^{\mathbf{0}} \\
\text { matrículas de alunos }\end{array}$ & $\begin{array}{l}\text { \% } \\
\text { com acesso à } \\
\text { biblioteca/sala } \\
\text { de leitura }\end{array}$ \\
\hline Fundamental & Pública & 118.914 & 43,9 & 24.694 .440 & 75,7 \\
\cline { 2 - 6 } & Privada & 22.346 & 84,4 & 4.374 .841 & 90,7 \\
\hline \multirow{2}{*}{ Médio } & Pública & 19.400 & 87,7 & 7.247 .776 & 92,2 \\
\cline { 2 - 6 } & Privada & 8.050 & 93,2 & 1.065 .039 & 94,3 \\
\hline
\end{tabular}

Fonte: BRASIL, 2014, p. 34-35.

Esses números indicam que, no Brasil, a biblioteca está ausente para muitos alunos do ensino fundamental, numa fase da vida escolar em que o acesso e uso dos livros e de outros materiais informativos poderiam ter influência positiva no seu letramento. A biblioteca falta, principalmente, para alunos com mais dificuldade de acesso a esses recursos fora da escola, isto é, aqueles que frequentam a escola pública. Os indicadores melhoram em escolas particulares e também no nível médio. Teoricamente a biblioteca escolar tem sido, há longo tempo, reconhecida como essencial ao processo de aprendizagem: "Ensino e biblioteca não se excluem, completam-se. Uma escola sem biblioteca é instrumento imperfeito", já dizia o educador brasileiro Lourenço Filho, na década de 1940 (LOURENÇO FILHO, 1946).

\footnotetext{
${ }^{2}$ A educação básica atende alunos de 0 a 17 anos. É dividida em: Educação Infantil, que atende alunos de 0 a 5 anos; Ensino Fundamental, alunos de 6 a 14 anos; Ensino Médio, de 15 a 17 anos.
} 
O discurso dos segmentos sociais envolvidos com a educação no país é pródigo em reforçar a importância da biblioteca escolar. Diversos documentos de políticas públicas do setor educacional enfatizam o valor da biblioteca escolar principalmente na formação de leitores (BRASIL, 1997; PAIVA; BERENBLUM, 2009). A classe bibliotecária também reconhece a importância de uma boa biblioteca na escola e vem se esforçando permanentemente para mostrar seu valor na melhoria da educação (CAMPELLO, 2003).

\section{Diagnósticos de bibliotecas escolares}

Desde 1979, pelo menos dezoito estudos que coletaram dados sobre essas bibliotecas confirmaram suas frágeis condições e mostraram preocupação e, em alguns casos, indignação, com a situação (CAMPELLO et al., 2012³). Os diagnósticos analisaram conjuntos de bibliotecas de determinadas regiões, com a intenção clara de expor situações precárias e de sensibilizar para mudanças, focalizando, portanto, prioritariamente, suas deficiências.

Pode-se dizer, então, que a situação da biblioteca escolar no país ainda não foi equacionada. A presença de boas bibliotecas é limitada a poucas escolas (geralmente da rede privada e localizadas em cidades de maior porte, especialmente nas capitais de estados das regiões Sudeste e Sul).

Em 2009, por iniciativa do MEC, com a participação da Organização dos Estados IberoAmericanos, foi realizado um amplo estudo que resultou no documento Avaliação das Bibliotecas Escolares no Brasil (MEC; ORGANIZAÇÃO, 2011), que mostrou que as políticas públicas de distribuição de livros, que constituíram os principais instrumentos para a melhoria dos níveis de leitura de alunos do ensino básico no Brasil, pouca influência tiveram no aperfeiçoamento das bibliotecas das escolas públicas. A amostra do estudo foi composta por duzentas escolas selecionadas aleatoriamente entre 43.717 escolas públicas das redes federal, estadual e municipal ${ }^{4}$, que ofereciam Ensino Fundamental e/ou Ensino Médio e que possuíam biblioteca ou sala de leitura ${ }^{5}$. As cinco regiões (Norte, Nordeste, Centro-Oeste, Sudeste e Sul)

\footnotetext{
${ }^{3}$ O estudo de Campello et al. Situação das bibliotecas escolares no Brasil: o que sabemos? - reuniu dezoito diagnósticos publicados de 1979 a 2011, e analisou seus objetivos, metodologia, técnica de coleta de dados, referencial teórico, resultados, conclusões e recomendações.

${ }^{4}$ A rede federal está representada na amostra com seis escolas, a rede estadual com 91 escolas e a rede municipal com 103.

${ }^{5}$ Embora não exista uma distinção formal entre os termos biblioteca e sala de leitura, há concordância de que a última constitui um ambiente mais acanhado e sem a presença de um bibliotecário graduado. No estudo do MEC os próprios entrevistados é que definiram se o espaço era uma biblioteca ou uma sala de leitura.
} 
Bernadete Santos Campello

foram representadas, respectivamente pelos seguintes Estados: Acre, Bahia, Goiás, Rio de Janeiro e Santa Catarina. Duzentos diretores e/ou coordenadores pedagógicos; duzentos responsáveis por bibliotecas; seiscentos professores e 1200 alunos, responderam questionários e/ou foram entrevistados.

O estudo do MEC confirmou alguns dos resultados de diagnósticos anteriores, como pode ser visto a seguir.

- A falta de percepção de vínculo entre a biblioteca escolar e o projeto pedagógico da escola

A biblioteca existe como um apêndice, muitas vezes, segundo o estudo, como um "incomodo" que ocupa "um espaço que poderia ser destinado a salas de aula" (MEC; ORGANIZAÇÃO, 2011). Na verdade, muitas vezes acontece de ser a biblioteca desmontada para seu espaço se transformar em sala de aula. Há pouca participação da comunidade escolar no planejamento das atividades da biblioteca, dificultando sua inserção no currículo.

O professor entende a importância da biblioteca, mas pouco a utiliza como espaço de potencialização do trabalho de sala de aula. $\mathrm{O}$ funcionário que atua na biblioteca parece bastante deslocado das atividades escolares como um todo, não interagindo com o trabalho pedagógico.

\section{- A falta de profissionais especializados}

Os responsáveis pela biblioteca são, na sua maioria, professores, o que a primeira vista pode ser considerado um ponto positivo dada a possibilidade de, contando-se com esse profissional, se desenvolver projetos pedagógicos na biblioteca. Entretanto, há diversos aspectos negativos: são geralmente professores readaptados, sem treinamento específico para a função, ou então dividem seu tempo na biblioteca com outra função na escola. Também é esse professor que, quando falta algum docente, assume a regência da turma, ficando a biblioteca fechada nessas ocasiões.

O número de bibliotecários graduados presentes nas bibliotecas escolares é baixo: no estudo do MEC variou entre 34,8\% (Santa Catarina) a nenhum (Acre). Outros estudos (CAMPELLO et al., 2012) mostraram que há variação nesses percentuais, dependendo da região e da vinculação das bibliotecas (se de escolas públicas ou particulares). A ausência de um profissional especializado para assumir a responsabilidade pela biblioteca traz diversas 
Bibliotecas escolares e Biblioteconomia escolar no Brasil

consequências, desde a desativação do espaço, passando pela limitação de horário de atendimento até a precariedade dos serviços oferecidos.

\section{- A precariedade do espaço físico}

Embora a maioria das escolas conte com espaço próprio para o que chama de biblioteca escolar, observam-se vários problemas com relação a esse espaço. São espaços exíguos, reaproveitados de salas de aula convencionais, na maioria de $50 \mathrm{~m}^{2}$. Algumas compartilham o espaço com outras atividades como, por exemplo, fotocopiadora, sala de informática, secretaria da escola. A falta de espaço é um fator limitador, impossibilitando a realização de atividades com uma turma inteira ou com grupos maiores de alunos.

\section{- As características da coleção}

O acervo é formado principalmente por material destinado aos alunos, recebido por doações, seja do Programa Nacional Biblioteca da Escola - $\mathrm{PNBE}^{6}$ ou de outras agências governamentais, e complementado por meio de campanhas organizadas pela própria escola. Muitos acervos são formados predominantemente por livros didáticos e, em alguns casos, a biblioteca é utilizada como espaço de armazenagem e distribuição desses livros. Poucas bibliotecas contam com recursos específicos para a aquisição de material.

As coleções são diversificadas, e incluem livros, jornais, revistas, recursos audiovisuais, jogos, mapas. Parece que só agora os acervos das bibliotecas começam a apresentar um aumento resultante do envio do material do PNBE, implementado em 1997. Entretanto, esse rico e variado acervo não é utilizado adequadamente. Os livros recebidos costumam ficar empacotados em suas embalagens originais ou guardados em armários trancados a chave, indisponíveis para consulta.

\footnotetext{
${ }^{6}$ O PNBE (http://www.jusbrasil.com.br/legislacao/821233/decreto-7084-10), apesar de sua denominação ampla, é um projeto anual que visa a dotar as escolas públicas com livros literários e de referência e outros materiais de bibliotecas. A seleção dos livros é realizada por instituições públicas de ensino superior, de acordo com as diretrizes e critérios estabelecidos pelo Ministério da Educação.
} 
- A pobreza dos serviços oferecidos

Os serviços mais oferecidos são o empréstimo domiciliar e a consulta no local, situação coerente com a falta de pessoal especializado: são serviços rotineiros, que não exigem planejamento ou ação proativa do funcionário, além de não demandarem integração com o corpo docente. Confirma também o sentido que os usuários têm da biblioteca: coleção de livros. Não há programas sistemáticos e persistentes de ensino de habilidades informacionais, embora o conceito de information literacy esteja sendo discutido nas instâncias acadêmicas da biblioteconomia.

\section{- A inadequação do tratamento técnico do acervo}

As técnicas para organização do acervo não seguem em geral a norma padrão, utilizando-se, em alguns casos, cores para cada área do conhecimento. Sistemas informatizados são raros em bibliotecas de escolas públicas, embora atualmente observe-se que algumas redes de bibliotecas começam a adquirir softwares especializados. O controle de empréstimo é feito manualmente, por meio de fichas ou cadernos.

Com relação à organização, observa-se uma situação peculiar. Quando o responsável é um bibliotecário graduado há maior investimento na organização técnica do acervo e quando é um professor, o investimento maior é nas atividades de estímulo à leitura, ou seja, parece que não se chega a um funcionamento harmonioso, que equilibre um acervo bem organizado com o oferecimento de serviços adequados.

A falta de organização técnica traz consequências: a biblioteca permanece como domínio particular do funcionário que ali atua. É somente ele que conhece todo o acervo, que sabe encontrar os livros, quem levou o livro emprestado, entre outras coisas, configurando uma organização pessoal e não técnica.

\section{- Possibilidade de acesso à internet}

Não há dados consistentes sobre o acesso à internet nas bibliotecas. Alguns estudos indicam que equipamentos e tecnologias começam, de maneira tênue, a ter presença nas bibliotecas das escolas públicas. O censo educacional de 2012 (BRASIL, 2013) indicou a existência de acesso à internet em 44,8\% das 122716 escolas públicas que oferecem ensino fundamental. Esse número aumenta de forma significativa nas escolas privadas e no ensino 
médio, repetindo a tendência já observada com relação à existência da biblioteca/sala de leitura. A TAB. 2 a seguir mostra as porcentagens.

TABELA 2 - Alunos com acesso à internet

\begin{tabular}{|l|l|l|c|l|l|}
\hline $\begin{array}{l}\text { Nível de } \\
\text { ensino }\end{array}$ & Vinculação & $\begin{array}{l}\mathrm{N}^{\mathbf{o}} \text { de } \\
\text { escolas }\end{array}$ & $\begin{array}{l}\text { \% de escolas } \\
\text { com acesso à } \\
\text { internet }\end{array}$ & $\begin{array}{l}\mathrm{N}^{\mathbf{2}} \text { de } \\
\text { matrículas }\end{array}$ & $\begin{array}{l}\text { \% de alunos } \\
\text { com acesso à } \\
\text { internet }\end{array}$ \\
\hline \multirow{2}{*}{$\begin{array}{l}\text { Fundament } \\
\text { al }\end{array}$} & Rede pública & 118.914 & 47,6 & 24.694 .440 & 82,3 \\
\cline { 2 - 7 } & Rede privada & 22.346 & 92,0 & 4.374 .841 & 96,8 \\
\hline \multirow{2}{*}{ Médio } & Rede pública & 19.400 & 93,2 & 7.247 .776 & 96,4 \\
\cline { 2 - 6 } & Rede privada & 8.050 & 98,1 & 1.065 .039 & 98,8 \\
\hline
\end{tabular}

Fonte: Brasil, 2014, p. 34-35.

Atualmente existem três programas governamentais a nível federal que visam a ampliar o acesso à internet nas escolas:

- Programa Nacional de Tecnologia Educacional - PROINFO $^{7}$, criado em 1997, como Programa Nacional de Informática na Educação, que objetiva promover o uso pedagógico das tecnologias de informática e telecomunicações nas escolas públicas de ensino fundamental e médio das redes estadual e municipal com a implementação de ambientes tecnológicos equipados com computadores e recursos digitais nas escolas, ou seja, laboratórios de informática.

- Programa Nacional de Banda Larga - $\mathrm{PNBLE}^{8}$, criado em 2008, com a finalidade de conectar todas as escolas públicas urbanas à internet, viabilizando a instalação de infraestrutura da rede, e garantindo a manutenção dos serviços sem ônus até o ano de 2025.

- Programa Um Computador por Aluno - PROUCA 9 teve início em 2010, objetivando promover a inclusão digital por meio da distribuição de um computador portátil equipado para rede sem fio e conexão a Internet para cada estudante e professor de Educação Básica em escolas públicas.

A tendência, portanto, é o aumento do acesso aos equipamentos, mas não se sabe como as bibliotecas escolares irão utilizar o recurso para ampliar seus acervos e potencializar seus serviços.

\footnotetext{
${ }^{7}$ http://portal.mec.gov.br/index.php?Itemid=462

${ }^{8} \mathrm{http} / / /$ portal.mec.gov.br/index.php?Itemid=823\&id=15808\&option=com_content \&

${ }^{9} \mathrm{http} / / /$ portal.mec.gov.br/index.php?option=com_content $\&$ task=view\&id=11833
} 
Bernadete Santos Campello

Essa análise dos principais problemas que afetam as bibliotecas escolares brasileiras pode ser encerrada com a observação feita no documento Avaliação das Bibliotecas Escolares no Brasil:

\begin{abstract}
Observa-se, no caminhar histórico da construção do espaço da biblioteca, que há convivência com um mundo sofisticado e acelerado pelas inovações tecnológicas e um outro que ainda não se apropriou do código da escrita e da leitura, traduzida nas próprias bibliotecas pela ausência de equipamentos e de tecnologias, em que o livro permanece como objeto primordial... (MEC; ORGANIZAÇÃO, 2011).
\end{abstract}

\title{
Biblioteconomia escolar no Brasil
}

Nesta parte do trabalho serão abordadas ações relativas aos seguintes aspectos: formação de bibliotecários, pesquisa, eventos, publicações e movimento associativo.

\section{Formação do bibliotecário}

A educação formal de bibliotecários no Brasil teve início em 1915, com a criação de um curso de biblioteconomia na Biblioteca Nacional, no Rio de Janeiro, que tinha como finalidade a formação de especialistas para o trabalho na própria Biblioteca. O curso tinha um viés humanista, com forte influência francesa da École de Chartes, ligada à biblioteca nacional francesa. O segundo curso foi criado em São Paulo, em 1929, no Mackenzie College, sob a coordenação da bibliotecária norte-americana Dorothy Muriel Gedds Gropp, sob influência do curso de biblioteconomia da Columbia University. Em 1936, foi criado o Curso de Biblioteconomia do Departamento de Cultura da Prefeitura de São Paulo. Nas décadas de 1940 e 1950 foram criados mais sete cursos (VALENTIM, 2002).

Em 1962, a Biblioteconomia foi elevada a status de profissão de nível superior; os cursos existentes foram assimilados por universidades e outros foram criados e houve a padronização das disciplinas, por meio do primeiro Currículo Mínimo, definido pelo Ministério da Educação. Em 1982, houve uma atualização curricular com o estabelecimento do segundo Currículo Mínimo, que definiu a divisão das disciplinas em três grupos: matérias de fundamentação geral, matérias instrumentais e matérias de formação profissional. Na década de 1990, com a modernização da educação brasileira, os Currículos Mínimos do ensino superior foram substituídos por Diretrizes Curriculares, que proporcionaram mais liberdade às instituições de ensino superior para definir seus currículos, abrindo aos cursos a possibilidade de organizarem 
seus projetos pedagógicos de acordo com seus interesses. A flexibilização curricular, tendência presente nos currículos atuais, permite que os alunos componham sua trajetória acadêmica, dentro de limites definidos pelos cursos (VALENTIM, 2002).

Segundo informações datadas de 2013, obtidas no site do Conselho Federal de Biblioteconomia - CFB, existiam 39 cursos de formação do bacharel em Biblioteconomia, sendo 25 em universidades públicas e treze em instituições particulares. Observa-se, pela TAB. 3, grande concentração de cursos na Região Sudeste, formada pelos estados mais desenvolvidos.

TABELA 3 - Número de cursos de Biblioteconomia por região

\begin{tabular}{|l|l|l|l|}
\hline \multirow{2}{*}{ Regiões } & \multicolumn{2}{|l|}{ Número de cursos } & \multirow{2}{*}{ Tota } \\
\cline { 2 - 3 } & Públicos & Particulares & 1 \\
\hline Norte & 2 & 0 & 2 \\
\hline Nordeste & 8 & 0 & 8 \\
\hline Centro-Oeste & 3 & 2 & 5 \\
\hline Sudeste & 7 & 10 & 17 \\
\hline Sul & 6 & 1 & 7 \\
\hline TOTAL & 26 & 13 & 39 \\
\hline Fonte: Conselho, [20--?]
\end{tabular}

A formação é feita em cursos de quatro anos de duração e com carga horária mínima de 2500 horas, incluídas as dedicadas a estágios e atividades complementares. A formação é generalista, preparando para atuação em qualquer tipo de biblioteca.

\section{Formação do bibliotecário escolar}

A diversificação na formação no nível de graduação, que resulte em um perfil mais voltado a determinado tipo de biblioteca, pode se dar nos cursos de graduação por meio de disciplinas optativas, estágios e atividades complementares. Mas a maioria dos cursos não oferece tais disciplinas, além do que os alunos costumam privilegiar estágios em bibliotecas universitárias e especializadas, que é onde se encontram maiores e melhores oportunidades de emprego. Assim, a formação específica do bibliotecário escolar não ocorre na graduação. Há, entretanto, um desejo constantemente manifestado pela classe, de que sejam inseridas nos currículos disciplinas de cunho pedagógico, de forma a oferecer uma formação mais direcionada para atuação em bibliotecas escolares (SANTOS, 1996; SILVA, 2005). Mas a formação generalista do bibliotecário no nível de graduação é uma prática que deve permanecer. Em consequência, aqueles poucos estudantes que têm interesse em uma carreira na 
Bernadete Santos Campello

biblioteconomia escolar buscam complementação em cursos de especialização (360 h) em áreas correlatas, geralmente, após já estarem inseridos no mercado de trabalho.

Cursos de especialização na área de biblioteconomia escolar ${ }^{10}$ (alguns deles à distância) começam a ser oferecidos após a promulgação da Lei 12244 de 24 de maio de 2010 (BRASIL, 2010), que dispõe que todas as escolas do país contem com uma biblioteca. Esses cursos, de 360hs em nível de pós-graduação, entretanto, costumam não ter um oferecimento regular, dependendo da existência de candidatos, que em geral, não é abundante e não conferem o grau formal do bacharelado em biblioteconomia. (MORO, ESTABEL, 2012; CHAGAS, 2012).

A fim de aumentar a quantidade de bibliotecários graduados, o Ministério da Educação disponibilizou recursos para a oferta de cursos de bacharelado em Biblioteconomia na modalidade à distância, a ser ofertado por universidades públicas (federais, municipais ou municipais) que possuam o curso na modalidade presencial. A Universidade Federal do Rio de Janeiro - UFRJ foi a instituição escolhida para o desenvolvimento de material didático e de apoio ao curso, que deverá ser oferecido no âmbito da Universidade Aberta do Brasil - UAB ${ }^{11}$. O fato de que um curso de graduação de Biblioteconomia à distância, de uma instituição privada, com inscrições abertas em $2013^{12}$, não teve início por falta de candidatos, pode estar apontando para algumas possibilidades: falta de interesse pela carreira, os candidatos não estão dispostos a pagar mensalidades, a característica da instituição ofertante que não tem tradição na área de Biblioteconomia.

\footnotetext{
${ }^{10}$ Cursos de Especialização em Biblioteca Escolar foram oferecidos nas seguintes universidades: UFSC, UEL, UFRGS, UFAM.

11 http://uab.capes.gov.br/index.php?option=com_content\&view=article\&id=206:ufrj-ira-desenvolver-materialdidatico-para-curso-de-biblioteconomia-da-uab\&catid=1:noticia\&Itemid=7

${ }^{12}$ Informações sobre o curso estão disponíveis em:

http://inscricaoead.universo.edu.br/polos/biblioteconomia/\#course-info
} 
A pesquisa acadêmica na área de Biblioteconomia no Brasil teve início na década de 1970, quando começaram a ser criados os cursos de pós-graduação no nível de mestrado, seguidos, na década de 1990, pelos cursos de doutorado, cuja implantação se deu quando a maioria dos programas, que tiveram início como cursos de Biblioteconomia, já haviam mudado para Ciência da Informação. Mesmo com essa nova denominação, a maioria dos programas continuou a acolher projetos sobre temas bibliotecários, entre eles a biblioteca escolar. Entretanto, a primeira dissertação de mestrado e a primeira tese de doutorado tratando da biblioteca escolar foram defendidas na área de educação, em 1975 e 1992, respectivamente (CAMPELLO et al., 2013).

Desde o início da pós-graduação em Biblioteconomia/Ciência da Informação no Brasil, alguns levantamentos esporádicos revelaram a pequena produção de pesquisas na área de biblioteca escolar. Um estudo de citações publicado em 2007 (CAMPELLO et al., 2007) identificou, no período de 1975 a 2002, 39 relatos de pesquisa sobre biblioteca escolar, dentre os quais 35 teses e dissertações.

Estudo mais recente (CAMPELLO et al., 2013), cobrindo o período de 1975 a 2011, identificou noventa e um estudos sobre biblioteca escolar, entre teses (07), dissertações (31), artigos de periódicos (10) e trabalhos de eventos (22). Desses, foram localizados, obtidos em texto completo e analisados setenta estudos, cujos subtemas foram assim definidos:

$\begin{array}{lc}\text { Biblioteca escolar como espaço de aprendizagem: } & 11 \text { estudos } \\ \text { Integração professor/bibliotecário: } & 08 \text { estudos } \\ \text { Estudos de usos e usuários: } & 13 \text { estudos } \\ \text { Coleção: } & 06 \text { estudos } \\ \text { Leitura: } & 17 \text { estudos } \\ \text { Pesquisa escolar: } & 15 \text { estudos }\end{array}$

O tradicional envolvimento da biblioteca escolar com a leitura reflete na quantidade de estudos deste subtema que é o mais numeroso (17 estudos). Por outro lado, a preocupação em entender melhor a questão da pesquisa escolar, que vem em segundo lugar em número de estudos (15), demonstra que a área está buscando conhecimento para embasar sua ação educativa que se amplia para além da leitura, e incorpora questões ligadas à competência informacional. Observa-se que o último estudo sobre leitura é de 2007, enquanto que o último 
sobre pesquisa escolar é de 2011, podendo ser isso um sinal de mudança de foco dos pesquisadores. Outro aspecto que a análise revelou foi a certeza de que, no desempenho de sua função educativa, o bibliotecário tem que trabalhar em colaboração com o professor (subtema com 08 estudos), em consonância com os objetivos da escola. Os estudos de uso e usuários, embora em número significativo (13), ainda estão presos a uma abordagem tradicional, não conseguindo realizar um diálogo efetivo com a questão pedagógica, essencial na biblioteca escolar.

Uma conclusão importante dessa análise (CAMPELLO et al., 2013) foi que falta clareza no uso do referencial teórico dos estudos. Embora esse problema pareça estar sendo superado, há, ainda, uma parcela considerável de estudos que não utiliza um referencial teórico definido, representando uma fragilidade teórica. Outra conclusão foi que, seguindo uma tendência internacional (CLYDE; OBERG, 2004; OBERG, 2006; MARDIS, 2009) o conhecimento acadêmico sobre biblioteca escolar no Brasil se encontra em expansão, podendo ampliar o entendimento das questões que envolvem o tema, sustentar uma prática baseada em evidências, além de possibilitar o apoio a ações políticas que levem ao aperfeiçoamento das bibliotecas escolares do país.

Destacam-se os seguintes grupos acadêmicos que realizam pesquisas e outras ações voltadas para a biblioteca escolar:

- Colaboratório de Infoeducação - Colabori $^{13}$, coordenado pela Profa. Ivete Pieruccini, sediado no Departamento de Biblioteconomia e Documentação, da Escola de Comunicação e Artes da Universidade de São Paulo, tem como foco as relações entre biblioteca escolar e educação, a geração e redefinição de conceitos, metodologias e práticas ligadas às noções de biblioteca escolar como dispositivo educacional, informacional e cultural.

- Grupo de Estudos em Biblioteca Escolar - GEBE ${ }^{14}$, coordenado pela Profa. Bernadete Campello e sediado na Escola de Ciência da Informação da UFMG integra pesquisadores e estudantes em torno de atividades de ensino, pesquisa e extensão relacionadas especialmente à função educativa da biblioteca, procurando uma melhor compreensão do potencial dessa instituição como espaço de aprendizagem.

- Grupo de Pesquisa Comportamento e Competência Informacionais ${ }^{15}$, coordenado pela Profa. Helen de Castro Silva Casarin, do Departamento de Ciência da Informação da

\footnotetext{
${ }^{13} \mathrm{http}: / /$ www.eca.usp.br/nucleos/colabori/

${ }^{14} \mathrm{http}: / /$ gebe.eci.ufmg.br/

${ }^{15} \mathrm{http}: / /$ plsql1.cnpq.br/buscaoperacional/detalhegrupo.jsp?grupo=0330607Y5FR07H
}

Bibl. Esc. em R., Ribeirão Preto, v. 4, n. 1, p. 1-25, 2015. 
Universidade Estadual Paulista Júlio de Mesquita Filho, na cidade de Marília, SP., é fruto do trabalho de pesquisas que vêm sendo desenvolvidas por docentes e alunos desde 2005. Embora o foco dos estudos do Grupo seja a competência informacional, há uma ênfase na biblioteca e no bibliotecário escolar, já que o Grupo realiza estudos sobre o desenvolvimento de estratégias para o ensino destas habilidades junto a diferentes grupos de usuários.

- Grupo de Pesquisa Práticas e Reflexões sobre Biblioteca Escolar ${ }^{16}$, coordenado pelo Prof. Cláudio Marcondes de Castro Filho, funciona, desde 2010, no Departamento de Educação, Informação e Comunicação da Faculdade de Filosofia, Ciências e Letras de Ribeirão Preto da Universidade de São Paulo. O Grupo atua em duas linhas de pesquisa: 1) Discursos em e sobre biblioteca escolar, que pretende explorar os discursos, científico e midiático, sobre a biblioteca escolar, observando os sentidos que se formam sobre ela, escutando a voz de sujeitos leitores e bibliotecários; 2) Profissional da informação: reflexões sobre o bibliotecário escolar, que estuda o papel do bibliotecário escolar, com base na investigação de políticas públicas e das práticas realizadas na biblioteca escolar.

\section{Eventos}

A classe bibliotecária no Brasil conta com dois eventos gerais, onde têm oportunidade de apresentar e discutir suas pesquisas e suas práticas:

- Congresso Brasileiro de Biblioteconomia, Documentação e Ciência da Informação $C B B D$, promovido desde 1954 pela Federação Brasileira de Bibliotecários, Cientistas da Informação e Instituições - FEBAB, em parceria com associações filiadas, sendo um evento consolidado no cenário nacional, funcionando como um espaço para apresentação e discussão principalmente de práticas profissionais,

- Encontro Nacional de Pesquisa em Ciência da Informação - ENANCIB é um evento de pesquisa, organizado pela Associação Nacional de Pesquisa em Ciência da Informação - ANCIB, desde 1994, onde são apresentadas e debatidas as investigações realizadas em instituições acadêmicas.

\footnotetext{
${ }^{16} \mathrm{http} / / /$ plsql1.cnpq.br/buscaoperacional/detalhegrupo.jsp?grupo=0067607PW6IRZ8
} 
Bernadete Santos Campello

Esses eventos acolhem também trabalhos sobre biblioteca escolar que são publicados nos respectivos anais. Eventos específicos na área de biblioteca escolar vêm ocorrendo de esporadicamente. Alguns desses foram:

- Seminário Biblioteca Escolar Espaço de Ação Pedagógica: o $1^{\circ}$ e o $3^{\circ}$ desses seminários foram organizados pelo GEBE, em 1998 e 2004 respectivamente, e tiveram chamada de trabalhos que foram publicados em anais que estão disponibilizados no site do grupo ${ }^{17}$.

- Fórum Internacional de Biblioteconomia Escolar - FIBE: foi realizado apenas duas vezes, em 2008 e em 2011, incorporando o IV e o V Seminário Biblioteca Escolar Espaço de Ação Pedagógica ${ }^{18}$. O FIBE, embora sem chamada de trabalhos, contou com a presença de convidados estrangeiros e constituiu ocasião para o debate de questões importantes sobre biblioteca escolar. Entretanto, essas participações não foram registradas em anais, limitando o impacto das apresentações e dos debates.

Em 2012, o Fórum de Pesquisa em Biblioteca Escolar, organizado pelo GEBE e realizado em Belo Horizonte, reuniu a liderança da biblioteconomia escolar no país e abriu caminho para o início da consolidação de um evento específico da área (CALDEIRA et al., 2012). No ano seguinte, o GEBE, em parceria com a representação da International Association of School Librarianship - IASL no Brasil e com o CFB, organizou o $1^{\circ}$ Fórum de Biblioteconomia Escolar: pesquisa e prática ${ }^{19}$, no âmbito do $25^{\circ}$ Congresso Brasileiro de Biblioteconomia, Documentação e Ciência da Informação. O Fórum reuniu, e pretende continuar reunindo, pesquisadores e profissionais atuantes no mercado de trabalho. Há expectativa de que a realização conjunta com o CBBD garanta sua permanência, tendo em vista o fato de que o CBBD constitui um evento já consolidado desde a década de 1950 (FERREIRA; TOLEDO; FERREIRA, 1979).

\footnotetext{
${ }^{17} \mathrm{http}$ //gebe.eci.ufmg.br/index.php?option=com_content\&view=article\&id=54\&Itemid=53

18 O $2^{\circ}$ Seminário Biblioteca Escolar Espaço de Ação Pedagógica foi realizado em Vitória, ES, em 1999, organizado pela Secretaria de Educação da Prefeitura Municipal de Vitória, ES., também sem registro em anais.

19 http://gebe.eci.ufmg.br/index.php?option=com_content $\&$ view=article \&id=109\&Itemid=95
} 
Publicações

As pesquisas acadêmicas geram teses e dissertações que são divulgadas virtualmente em repositórios institucionais ou bibliotecas digitais e que, algumas vezes, são publicadas como artigos em revistas da área de ciência da informação.

Existem quinze periódicos na área de ciência da informação listados no site da $\mathrm{ANCIB}^{20}$, mas apenas uma revista especializada em biblioteca escolar (Biblioteca Escolar em Revista ${ }^{21}$ ), de periodicidade semestral, que teve início em 2002 e que aceita principalmente artigos originados de pesquisas inéditas. Entretanto, falta uma publicação que leve os resultados das pesquisas até os profissionais e que estimule a prática baseada em evidências.

No que diz respeito a livros, percebe-se um lento aumento na produção, com algumas editoras comerciais se interessando pela temática da biblioteca escolar. Merece destaque a Autêntica Editora, que vem desde o ano 2000, publicando livros produzidos pelo GEBE, estando entre eles as traduções dos livros de Carol Kuhlthau: School Librarian's Grade by Grade Activities Program: a complete seqüencial skills plan for grades $K-8^{22}$ e Teaching the Library Research Process ${ }^{23}$.

Trabalhos de eventos são publicados em anais, sendo apenas dois os eventos consolidados na área de biblioteconomia/ciência da informação em geral, que oferecem oportunidade para a apresentação de trabalhos sobre biblioteconomia escolar: Congresso Brasileiro de Biblioteconomia, Documentação e Ciência da Informação - CBBD (25 em 2013) e Encontro Nacional de Pesquisa em Ciência da Informação (15 em 2014). Os organizadores de alguns eventos esporádicos sobre biblioteca escolar não têm se preocupado em produzir os anais e isso abre uma lacuna sobre o conhecimento e as ações sobre o tema.

A produção bibliográfica sobre biblioteca escolar é reunida na base de dados Literatura Brasileira em Biblioteca Escolar - LIBES ${ }^{24}$, de responsabilidade do GEBE e alimentada pela Biblioteca da Escola de Ciência da Informação da UFMG, onde o Grupo é sediado. A base procura referenciar toda a produção sobre o tema e contém atualmente cerca de 400 referências,

\footnotetext{
${ }^{20}$ http://www.ancib.org.br/

${ }^{21} \mathrm{http}: / /$ revistas.ffclrp.usp.br/berev

$22 \mathrm{http} / /$ grupoautentica.com.br/autentica/livros/como-usar-a-biblioteca-na-escola-um-programa-de-atividadespara-o-ensino-fundamental/51

${ }^{23} \mathrm{http}$ //grupoautentica.com.br/autentica/livros/como-orientar-a-pesquisa-escolar-estrategias-para-o-processo-deaprendizagem $/ 558$

${ }^{24} \mathrm{http}$ //gebe.eci.ufmg.br/index.php?option=com_content\&view=article\&id=49\&Itemid=40
}

Bibl. Esc. em R., Ribeirão Preto, v. 4, n. 1, p. 1-25, 2015. 
Bernadete Santos Campello

incluindo documentos publicados desde a década de 1960, remetendo para o documento completo quando disponível em formato digital.

\section{Movimento associativo e ações políticas}

O movimento associativo de bibliotecários é frágil no Brasil. Embora a maioria dos Estados conte com uma associação, elas são pouco ativas, desenvolvendo ações esparsas e que pouco impacto têm no aperfeiçoamento da classe ou das bibliotecas.

A FEBAB ${ }^{25}$, fundada em 1959, que reúne dezoito dessas associações estaduais, tem como principal missão defender e incentivar o desenvolvimento da profissão. Tem como objetivos coordenar e desenvolver atividades que promovam as bibliotecas e seus profissionais; apoiar as atividades de seus filiados e dos profissionais associados; atuar como centro de documentação, memória e informação das atividades de biblioteconomia, ciência da informação e áreas correlatas brasileiras; interagir com as instituições internacionais da área de informação; desenvolver e apoiar projetos na área, visando o aprimoramento das bibliotecas e dos profissionais; contribuir para a criação e desenvolvimento dos trabalhos das comissões e grupos de áreas especializadas.

Em 2013, no âmbito da FEBAB, foi criada a Comissão Brasileira de Bibliotecas Escolares, com a seguinte agenda:

- Trabalhar em colaboração com o Conselho Federal de Biblioteconomia, desenvolvendo ações que coloquem a biblioteconomia escolar nas agendas das políticas públicas de educação no Brasil.

- Promover o $2^{\circ}$ Fórum Brasileiro de Biblioteconomia Escolar - pesquisa e prática.

- Estimular a participação de bibliotecários brasileiros em eventos internacionais tais como os da IASL.

Sendo uma profissão regulamentada por lei (Lei 4084/1962), a biblioteconomia no Brasil conta com órgãos que têm a responsabilidade de fiscalizar o exercício profissional do bibliotecário. $\mathrm{O} \mathrm{CFB}^{26}$ é o órgão federal que coordena os quatorze Conselhos Regionais. Desde sua instalação em 1966, o CFB vem acompanhando o desenvolvimento da Biblioteconomia no

\footnotetext{
${ }^{25}$ http://www.febab.org.br/

${ }^{26}$ http://www.cfb.org.br/
}

Bibl. Esc. em R., Ribeirão Preto, v. 4, n. 1, p. 1-25, 2015. 
Brasil, não apenas realizando a missão de fiscalização do exercício profissional do bibliotecário, juntamente com os Conselhos Regionais, como também realizando e apoiando outras atividades relacionadas com a profissão. A mais recente ação do CFB foi a criação de uma Comissão de Bibliotecas Escolares e Públicas.

No que diz respeito às bibliotecas escolares, o CFB lançou, em 2008, o Projeto Biblioteca Escolar: construção de uma rede de informação para o ensino público (CONSELHO, 2008), buscando mobilizar a sociedade e os dirigentes governamentais para a necessidade de se criar bibliotecas em todas as escolas brasileiras. Um dos resultados desta ação foi a promulgação, no dia 24 de maio de 2010, da Lei $n^{\circ} 12.244$ que dispõe sobre a universalização das bibliotecas nas instituições educacionais do país. A lei determina que as escolas contem com um acervo de livros de, no mínimo, um título para cada aluno matriculado. Os sistemas de ensino são responsáveis pela ampliação deste acervo conforme sua realidade, bem como pelas diretrizes de manutenção, preservação, organização e funcionamento das bibliotecas escolares. A lei estabelece um prazo máximo de dez anos para sua efetivação, e recomenda que seja respeitada a profissão de Bibliotecário, disciplinada pelas Leis nos 4.084, de 30 de junho de 1962, e 9.674, de 25 de junho de 1998.

Alguns Conselhos Regionais têm uma ação mais ativa na promoção da biblioteca escolar. O CRB - 8 de São Paulo desencadeou, principalmente nos últimos dois anos, várias iniciativas no sentido de disseminar um novo conceito para as bibliotecas, baseado no documento Standards for the 21st Century Learner ${ }^{27}$, da Associação Americana de Bibliotecários Escolares (American Association of School Librarians - AASL), que foi traduzido para o português, com o título de Parâmetros para o aprendiz do século $21^{28}$.

O CRB - 10 do Rio Grande do Sul organiza, desde 2009, o Fórum Gaúcho pela Melhoria das Bibliotecas Escolares e Públicas, que tem como principal objetivo incentivar a criação de bibliotecas em cidades do interior do Estado. Realizado em parceria com diversas instituições públicas e privadas, o Fórum funciona por meio de reuniões em cada cidade escolhida, reunindo as lideranças educacionais locais, agentes governamentais, professores e educadores preocupados com a questão da biblioteca. Até o presente já foram realizadas cerca de 30

\footnotetext{
${ }^{27} \mathrm{http}: / /$ www.ala.org/aasl/sites/ala.org.aasl/files/content/guidelinesandstandards/learningstandards/AASL_Learni ngStandards.pdf

${ }^{28} \mathrm{https} / / /$ docs.google.com/file/d/1LQh5jCsglriXQqt8Glpsy0YbTm61BdAuWv4t7rYVHcmnjGDdPHxkTM0z2s AV/edit?hl=pt_BR\&pli=1
} 
Bernadete Santos Campello

reuniões, onde aconteceram palestras, relatos de experiências, workshops e minicursos (MORO, 2011).

Destaca-se na ação política, a iniciativa do Instituto Ecofuturo que, em parceria com organizações da sociedade civil, lançou em 2012 a campanha "Eu quero minha biblioteca ${ }^{29 ",}$ com a finalidade de informar gestores públicos, dirigentes educacionais, professores e demais interessados na biblioteca escolar sobre as ações legislativas para a implantação da Lei 12244.

\section{Padrões para bibliotecas escolares}

Outra ação no âmbito do Projeto Mobilizador (CFB, 2008) foi a busca de parcerias para atingir as metas propostas, que resultou na colaboração do GEBE, que se dispôs a elaborar parâmetros para criação e avaliação de bibliotecas escolares (GRUPO, 2010). Essa iniciativa se fundamentou no fato de que, embora a importância da biblioteca na escola seja reconhecida, há no país um desconhecimento generalizado das características que definem o que constitui realmente uma biblioteca escolar. Assim, partiu-se do princípio de que a melhor maneira de mostrar o que é uma verdadeira biblioteca escolar seria definir padrões que dessem aos interessados um ponto de partida para criar bibliotecas nas escolas que ainda não dispusessem desse recurso, e para avaliar e aperfeiçoar as bibliotecas já existentes.

\section{Conclusões}

A criação de grupos acadêmicos de pesquisa, a partir da década de 1990, e o consequente aumento de estudos sobre biblioteca escolar indicam que a fundamentação teórica para o aperfeiçoamento dessas instituições está sendo construída. A disponibilização de documentos sobre o tema na web e a existência da LIBES, uma base de dados consolidada e com garantia de atualização permanente, dão suporte à formação de bibliotecários comprometidos com o conhecimento sobre a biblioteca escolar, aptos a desenvolverem práticas mais embasadas em evidências.

A desejada consolidação de um evento na área, com apresentação de trabalhos e registro em anais, poderá fortalecer essa base, oferecendo oportunidade para discussão e divulgação de resultados de pesquisa e de relatos de melhores práticas.

\footnotetext{
${ }^{29}$ http://www.euquerominhabiblioteca.org.br/
} 
Bibliotecas escolares e Biblioteconomia escolar no Brasil

Por outro lado, faltam ações políticas mais efetivas, que convençam as lideranças governamentais a investir em ações na criação e no aperfeiçoamento de bibliotecas nas escolas. Os baixos índices alcançados pelo Brasil em indicadores educacionais como o Programme for International Student Assessment - PISA ${ }^{30}$ pode ser um fator que induza o governo federal a investir em programas mais efetivos de criação de bibliotecas escolares, considerando que a simples distribuição de livros, que favorece mais os editores do que os estudantes, já provou não estar funcionando, conforme demonstrado pela avaliação do PNBE, que verificou que

[...] muitas bibliotecas se confundiam com depósitos de livros amontoados sem nenhum critério nem organização e, muitas vezes, encontraram-se os livros empacotados em suas embalagens originais. Outras se reduziam a armariotecas, os livros encontravam-se guardados em armários trancados a chave, indisponíveis para consulta de alunos ou de professores. Em muitas bibliotecas não existiam registros dos livros em catálogos, o que implicava desconhecimento por parte da comunidade escolar sobre a quantidade e a qualidade das obras de que dispunham (PAIVA; BERENBLUM, 2009, p. 185-186).

Por outro lado, a pesquisa de 2011 (BRASIL, 2011), considerou que os investimentos feitos pelo governo federal na seleção e envio de acervos para as escolas têm sido um fator de mobilização das redes escolares na criação de uma "cultura de atenção a biblioteca escolar". Ao receber os acervos, as escolas precisam decidir sobre: onde colocá-los, como armazená-los e catalogá-los, quem vai cuidar do acervo e mobilizar ações para sua utilização. Essa mobilização resulta em investimentos próprios e definições político-pedagógicas das escolas, gerando, segundo os pesquisadores "expectativa de autonomia e de 'utilidade' para a biblioteca escolar" (BRASIL, 2011).

A efetividade da Lei 12244/2010, de universalização da biblioteca escolar, ainda está por ser comprovada. Embora a comunidade bibliotecária tenha dado demonstrações de estar esperançosa de que ela irá modificar a situação das bibliotecas escolares, também fez críticas ao texto da lei. Em primeiro lugar, considera que a concepção de biblioteca escolar da legislação é extremamente limitada, definindo biblioteca escolar como "a coleção de livros, materiais videográficos e documentos registrados em qualquer suporte destinados a consulta, pesquisa, estudo ou leitura" (BRASIL, 2010). O acervo de livros deve ser de, no mínimo, um título para cada aluno matriculado. Questões como organização e conservação do acervo e o funcionamento da biblioteca são tratadas superficialmente, delegando-se sua responsabilidade aos sistemas de ensino aos quais a escola é vinculada. Outra crítica é a falta de regras específicas

\footnotetext{
${ }^{30}$ As performances médias dos estudantes brasileiros no PISA em 2012, em matemática (391 pontos), leitura (410 pontos) e ciências (405) foram todas abaixo da média da OCDE.

(http://download.inep.gov.br/acoes_internacionais/pisa/resultados/2013/country_note_brazil_pisa_2012.pdf)
} 
para a criação das bibliotecas, de instrumentos de fiscalização do cumprimento das normas e de indicadores de qualidade.

O ponto forte da lei é a exigência do bibliotecário: a lei determina que a profissão seja respeitada de acordo com a legislação que a regulamenta ${ }^{31}$, a qual define que o exercício da profissão de bibliotecário é privativo do bacharel em Biblioteconomia. Embora a Lei não defina claramente que cada biblioteca deva ter um bibliotecário, o número de profissionais necessários para atender minimamente às suas exigências é uma questão que tem sido levantada, embora os números apresentados não sejam embasados em estudos científicos. De acordo com um levantamento divulgado pelo CFB em junho de 2013 ${ }^{32}$, existem 34805 bibliotecários registrados, mas apenas 18374 estão em atividade. A formação se dá em ritmo lento: de 2009 a 2012 o número total de concluintes dos cursos de graduação em Biblioteconomia foi de 5319 (ver Anexo 1), o que dá uma média de 1330 bibliotecários graduados por ano, nos últimos quatro anos. Considerando-se a quantidade de escolas do país (192.676), pode-se ter uma idéia do déficit de bibliotecários nos próximos sete anos, tempo restante para cumprimento da lei.

Apenas o Estado do Amazonas parece estar se preparando para cumprir a lei federal, e elaborou um projeto de lei ${ }^{33}$ para a criação das bibliotecas no Estado; mas esse projeto apenas espelha a lei federal, repetindo suas deficiências, e ainda se encontrava em tramitação em 2013.

Uma tendência que se observa no universo das bibliotecas escolares, tanto do sistema público quanto particular de ensino é a formação de redes de cooperação. São esquemas com características diversificadas que buscam otimizar aspectos dessas bibliotecas, tais como o compartilhamento de um bibliotecário (que supervisiona diversas bibliotecas), o processamento técnico (com aquisição coletiva de software), programas de formação de pessoal, desenvolvimento de políticas unificadas de desenvolvimento de acervos, etc. Mas os contornos dessa tendência ainda não são muito claros ${ }^{34}$.

Os anais de um evento ocorrido em 1982 - o $1^{\circ}$ Seminário Nacional sobre Bibliotecas Escolares - revelavam as preocupações dos participantes, em mostrar o panorama ideal das bibliotecas escolares no contexto da educação e as recomendações apresentadas ao final do

\footnotetext{
${ }^{31}$ Lei 4084 de 30 de junho de 1962 e Lei 9674 de 25 de junho de 1998.

${ }^{32}$ http://www.cfb.org.br/UserFiles/File/Boletim\%20Especial\%20CFB.pdf

${ }^{33}$ file:///C:/Amazonas\%20Projeto\%20de\%20Lei\%20Ordin\%C3\%A1ria\%20n\%C2\%BA\%C2\%A0366\%202013\% 20de $\% 2013 \% 2011 \% 202013$. htm

${ }^{34}$ Um estudo em andamento no Programa de Pós-Graduação em Ciência da Informação da UFMG, do mestrando Rubeniki Fernandes de Limas, tem como objetivo compreender algumas características do funcionamento dessas redes.
} 
evento refletiam o desejo dos participantes de que o Brasil contasse com bibliotecas escolares de qualidade e reconhecidas como elementos fundamentais na aprendizagem (SEMINÁRIO, 1982). Nesses trinta anos muita coisa mudou e pode-se dizer que há um conhecimento mais sólido sobre a biblioteca escolar, em termos de pesquisas acadêmicas. No que diz respeito a dados estatísticos sobre a realidade dessas bibliotecas, há necessidade de se aperfeiçoar a coleta, caracterizando-se com mais rigor o que constitui uma biblioteca escolar, diferenciando bibliotecas de simples aglomerado de livros. Espera-se que os parâmetros para bibliotecas escolares (GRUPO, 2010) possam embasar a coleta de dados consistentes e realistas. Acreditase que o conhecimento acadêmico e boas estatísticas possam sustentar uma ação política que leve ao aperfeiçoamento das bibliotecas escolares do Brasil.

\section{Referências}

BRASIL. Lei $\mathrm{n}^{\circ}$ 12244, de 24 de maio de 2010. Dispõe sobre a universalização das bibliotecas nas instituições de ensino do País. Diário Oficial da União, Brasília, 25 maio 2010. Disponível em: <http://presrepublica.jusbrasil.com.br/legislacao/823116/lei-dabiblioteca-escolar-lei-12244-10>. Acesso em: 10 ago. 2015.

BRASIL. Ministério da Educação, Instituto Nacional de Estudos e Pesquisas Educacionais Anísio Teixeira. Censo da educação básica 2013: resumo técnico. Brasília, INEP, 2014. Disponível em:

<http://download.inep.gov.br/educacao_basica/censo_escolar/resumos_tecnicos/resumo_tecni co_censo_educacao_basica_2013.pdf>. Acesso em: 10 ago. 2015.

BRASIL. Ministério da Educação. Secretaria de Educação Fundamental. Parâmetros curriculares nacionais. Brasília: MEC/SEF, 1997. Disponível em:

<http://portal.mec.gov.br/seb/arquivos/pdf/livro02.pdf>. Acesso em: 10 ago. 2015.

CALDEIRA, P. T. et al. (Org.). Anais do $1^{0}$ Fórum de Pesquisa em Biblioteca Escolar. Belo Horizonte: GEBE, 2012. Disponível em:

<http://gebe.eci.ufmg.br/images/1forum2012/anais_verso_completa.pdf>. Acesso em: 10 ago. 2015 .

CAMPELLO, B. A função educativa da biblioteca escolar no Brasil: perspectivas para o seu aperfeiçoamento. In: ENCONTRO NACIONAL DE PESQUISA EM CIÊNCIA DA INFORMAÇÃO, 5., 2003, Belo Horizonte. Anais ... Belo Horizonte: ANCIB, 2003. Disponível em: <http://gebe.eci.ufmg.br/downloads/ENAN054.pdf>. Acesso em: 10 ago. 2015.

CAMPELLO, B. et al. Literatura sobre biblioteca escolar: características de citações de teses e dissertações brasileiras. Transinformação, Campinas, v. 19, n. 3, p. 227-236, 2007.

Disponível em: <http://periodicos.puccampinas.edu.br/seer/index.php/transinfo/article/view/547/527>. Acesso em: 10 ago. 2015. 
Pesquisas sobre biblioteca escolar no Brasil: o estado da arte. Encontros Bibli:

Revista Eletrônica de Biblioteconomia e Ciência da Informação, Florianópolis, v. 18, n. 37, p. 123-156, maio/ago., 2013. Disponível em:

<https://periodicos.ufsc.br/index.php/eb/article/viewFile/1518-

2924.2013v18n37p123/25335>. Acesso em: 10 ago. 2015.

Situação das bibliotecas escolares no Brasil: o que sabemos? Biblioteca Escolar em

Revista, Ribeirão Preto, v. 1, n. 1, p. 1-29, 2012. Disponível em:

<http://revistas.ffclrp.usp.br/BEREV/article/view/101>. Acesso em: 10 ago. 2015.

CHAGAS, M. T. Curso de gestão de bibliotecas escolares: modalidade a distância, desenvolvido no Departamento de Ciência da Informação da UFSC. In: FÓRUM DE PESQUISA EM BIBLIOTECA ESCOLAR, 1., 2012, Belo Horizonte. Anais... Belo Horizonte: Grupo de Estudos em Biblioteca Escolar, 2012. p. 107 - 113. Disponível em: $<$ http://gebe.eci.ufmg.br/images/1forum2012/anais_verso_completa.pdf >. Acesso em: 10 ago. 2015 .

CLYDE, L. A.; OBERG, D. LIS journals as a source of evidence for evidence-based practice: the case of school libraries worldwide. In: IFLA GENERAL CONFERENCE AND COUNCIL, 70., 2004, Buenos Aires. Proceedings... Buenos Aires: IFLA, 2004.

CONSELHO FEDERAL DE BIBLIOTECONOMIA. Projeto mobilizador: biblioteca escolar construção de uma rede de informação para o ensino público. Brasília: Sistema CFB/CRBs, 2008. Disponível em:

<http://www.cfb.org.br/UserFiles/File/promobil/PROMOBILFINAL.pdf >. Acesso em: 10 ago. 2015.

CONSELHO REGIONAL DE BIBLIOTECONOMIA 6º REGIÃO MG/ES. Carreira. [20-?]. Disponível em: 〈http://www.crb6.org.br/carreira.php>. Acesso em: 10 ago. 2015.

FERREIRA, C. N. C.; TOLEDO, M. R. C.; FERREIRA, R. H. C. Jubileu dos Congressos de Biblioteconomia e Documentação: temários, autores, trabalhos apresentados e recomendações. In: CONGRESSO BRASILEIRO DE BIBLIOTECONOMIA E DOCUMENTAÇÃO, 10., 1979, Curitiba. Anais... Curitiba: Associação Bibliotecária do Paraná, 1979. v. 1, p. 51- 62.

GRUPO DE ESTUDOS EM BIBLIOTECA ESCOLAR/ CONSELHO FEDERAL DE BIBLIOTECONOMIA. Biblioteca escolar como espaço de produção do conhecimento: parâmetros para bibliotecas escolares brasileiras. Belo Horizonte, 2010. Disponível em: <http://www.cfb.org.br/MIOLO.pdf>. Acesso em: 10 ago. 2015.

LOURENÇO FILHO, M. B. O ensino e a biblioteca. Rio de Janeiro: Imprensa Nacional, 1946.

MARDIS, M. A. Introduction: a gentle manifesto on the relevance and obscurity of school libraries in LIS research. Library Trends, v. 58, n. 1, p. 1-8, Summer, 2009. 
MEC; ORGANIZAÇÃO DOS ESTADOS IBERO-AMERICANOS. Avaliação das bibliotecas escolares no Brasil. Brasília: Fundação SM Brasil, 2011. Disponível em: <http://www.oei.es/bibliobrasil.pdf>. Acesso em: 10 ago. 2015.

MORO, E. L. S.; ESTABEL, L. B. Especialização em bibliotecas escolares e acessibilidade: curso de especialização lato sensu em EAD. In: FÓRUM DE PESQUISA EM BIBLIOTECA ESCOLAR, 1., 2012, Belo Horizonte. Anais... Belo Horizonte: Grupo de Estudos em Biblioteca Escolar, 2012. p. 91 - 106. Disponível em:

<http://gebe.eci.ufmg.br/images/1forum2012/anais_verso_completa.pdf >. Acesso em: 10 ago. 2015.

MORO, E. L. S. et al. (Org.). Biblioteca escolar: presente!. Porto Alegre: Evangraf/CRB-10, 2011. Disponível em: <http://www.bibliotecaescolarpresente.org.br/biblioteca.pdf >. Acesso em: 04 jan. 2014.

OBERG, D. Editorial: school libraries worldwide as a source of evidence for evidence-based practice, 1995-2006. School Libraries Worldwide, v. 12, n. 2, p. i-xii, 2006.

PAIVA, J.; BERENBLUM, A. Programa Nacional Biblioteca da Escola (PNBE): uma avaliação diagnóstica. Pro-Posições, v. 20, n. 1, p. 173-188, 2009. Disponível em: <http://www.scielo.br/pdf/pp/v20n1/v20n1a10.pdf>. Acesso em: 10 ago. 2015.

SANTOS, J. P. O moderno profissional da informação: o bibliotecário e seu perfil face aos novos tempos. Informação \& Informação, Londrina, v. 1, n. 1, p. 5-13, jan./jun. 1996. Disponível em: <http://www.uel.br/revistas/uel/index.php/informacao/article/view/1613>. Acesso em: 10 ago. 2015.

SEMINÁRIO NACIONAL SOBRE BIBLIOTECAS ESCOLARES, 1., 1982, Brasília. Anais... Brasília: INL/CERLALC, 1982.

SILVA, J. L. C. Perspectivas históricas da biblioteca escolar no Brasil e análise da lei 12.244/10. Revista ACB: Biblioteconomia em Santa Catarina, v. 16, n. 2, p. 489-517, 2011.

SILVA, A. P. Recursos humanos: debatedores. In: MACEDO, N. D. (Org.). Biblioteca escolar brasileira em debate: da memória profissional a um fórum virtual. São Paulo: SENAC/CRB8, 2005. p. 362-363.

VALENTIM, M. L. P. (Org.). Formação do profissional da informação. São Paulo: Polis, 2002. 
Bernadete Santos Campello

\section{ANEXO 1}

Ministério da Educação

Instituto Nacional de Estudos e Pesquisas Educacionais Anísio Teixeira

\section{CONCLUINTES DE CURSOS DE GRADUAÇÃO NA ÁREA DE BIBLIOTECONOMIA}

Número de concluintes de cursos de graduação na área de Biblioteconomia - série (2009 a 2012)

\begin{tabular}{|l|l|l|l|}
\hline \multirow{2}{*}{ Ano Censo } & Código OCDE Área Curso & Nome OCDE Área Curso & CONCLUINTES \\
\hline & $322 \mathrm{~A} 01$ & ARQUIVOLOGIA & 246 \\
\cline { 2 - 4 } & $322 \mathrm{~B} 01$ & BIBLIOTECONOMIA & 1.164 \\
\cline { 2 - 4 } & $322 \mathrm{~B} 02$ & BUSCA DA INFORMAÇÃO & 31 \\
\cline { 2 - 4 } & $322 \mathrm{C} 01$ & CIÊNCIA DA INFORMAÇÃO & 79 \\
\hline \multirow{2}{*}{2010} & $322 \mathrm{~A} 01$ & ARQUIVOLOGIA & 356 \\
\cline { 2 - 4 } & $322 \mathrm{~B} 01$ & BIBLIOTECONOMIA & 1.416 \\
\cline { 2 - 4 } & $322 \mathrm{C} 01$ & CIÊNCIA DA INFORMAÇÃO & 23 \\
\hline \multirow{2}{*}{2011} & $322 \mathrm{~A} 01$ & ARQUIVOLOGIA & 370 \\
\cline { 2 - 4 } & $322 \mathrm{~B} 01$ & BIBLIOTECONOMIA & 1.377 \\
\cline { 2 - 4 } & $322 \mathrm{C} 01$ & CIÊNCIA DA INFORMAÇÃO & 36 \\
\hline & $322 \mathrm{~A} 01$ & ARQUIVOLOGIA & 379 \\
\cline { 2 - 4 } & $322 \mathrm{~B} 01$ & BIBLIOTECONOMIA & 1.362 \\
\cline { 2 - 4 } & $322 \mathrm{C} 01$ & CIÊNCIA DA INFORMAÇÃO & 28 \\
\hline
\end{tabular}

Fonte: MEC/INEP/DEED/CSI (BI)

Notas: Foram considerados cursos de graduação da área de Biblioteconomia aqueles classificados como:

146F32 - Formação de Professor de Biblioteconomia;

146F41 - Formação de Professor de Arquivologia;

322A01 - Arquivologia;

322B01 - Biblioteconomia;

322B02 - Busca da Informação;

322C01 - Ciência da Informação;

322D01 - Documentação; e

322D02 - Documentação Museológica. 